\title{
Distribuição temporal e espacial da leishmaniose visceral em humanos e cães em Belo Horizonte-MG, 1993 a 2007
}

[Temporal and spatial distribution of leishmaniasis in humans and dogs from Belo Horizonte-MG, 1993-2007]

E.G.P. Lopes, D.F. Magalhães, J.A. Silva, J.P.A. Haddad, E.C. Moreira

Escola de Veterinária - UFMG

Av. Antônio Carlos, 6627

31270-901 - Belo Horizonte, MG

\begin{abstract}
RESUMO
O objetivo desta pesquisa foi descrever as análises da série cronológica e determinar a tendência da leishmaniose visceral em humanos e cães para o município de Belo Horizonte, de 1993 a 2007. De 1994, quando surgiram os primeiros casos da doença, até 2007, foram registrados 994 casos humanos autóctones com 116 óbitos. De 1993 a 2007, foram analisadas 1.492 .401 amostras de sangue canino com percentual de positividade de 5,9\%, utilizando-se os testes de enzyme-linked immunosorbent assay (ELISA) como triagem e de imunofluorescência indireta (IFI) como confirmatório. As análises indicaram que a leishmaniose visceral apresentou tendência crescente dos coeficientes de incidência em humanos e de prevalência em cães, e observaram-se arquétipos distintos dessa tendência, retratando o momento histórico de transição endêmica. A leishmaniose visceral em cães não apresentou características de distribuição sazonal, e não foi possível concluir a existência ou não de ciclicidade do fenômeno. A leishmaniose visceral em humanos e cães tem ampla distribuição espacial nas nove regionais administrativas com risco diferenciado de acometimento da doença, apesar da presença das fontes de infecção e dos susceptíveis em todo o município.
\end{abstract}

Palavras-chave: leishmaniose visceral, tendência, sazonalidade, ciclicidade

\begin{abstract}
The chronological series analysis and the tendencies of both human and canine visceral leishmaniasis were determined in Belo Horizonte city, from 1993 to 2007. From 1994, when the first cases of the disease were reported, until 2007, 994 human cases were recorded, which led to 116 deaths. From 1993 to 2007, 1,492,401 samples of canine blood were analyzed by the enzyme-linked immunosorbent assay (ELISA) as screening test and by the Indirect Immunofluorescence (IFI) as confirmatory test. The rate of positive results was $5.9 \%$. The analyses indicated that the visceral leishmaniasis presents a tendency of increasing the coefficient of incidence in humans and prevalence in dogs and different archetypes of this tendency were observed portraying historical moment of endemic transition. Canine visceral leishmaniasis did not show a seasonal distribution, and it was not possible to determine whether the phenomenon was cyclic or not. Human and canine visceral leishmaniasis showed a broad spatial distribution in the nine administrative sectors with a differentiated risk of illness, in spite of the presence either of the sources of infection or the susceptible individuals in the whole county.
\end{abstract}

Keywords: visceral leishmaniasis, tendency, seasonality, cyclic

\section{INTRODUÇÃO}

A leishmaniose visceral (LV) ou calazar, atualmente, está presente nas cinco regiões do Brasil (Leishmaniose..., 2009) e é um constante desafio para a saúde pública. Desde a década de 1970, vem sendo observado o fenômeno da urbanização crescente e mudanças no perfil epidemiológico clássico da doença (Oliveira et al., 2006).

A rápida e extensa expansão da $\mathrm{LV}$ pode ser explicada, em parte, pelas mudanças ambientais e pelas migrações intensas, acentuadas por

Recebido em 6 de abril de 2009

Aceito em 30 de agosto de 2010

E-mail: liziro@terra.com.br 
determinantes como ocupação desordenada e condições precárias de vida, inerentes aos centros urbanos. Nestes, o cão é considerado o principal reservatório doméstico, e estudos demonstram que altas taxas de prevalência canina estão associadas à ocorrência de casos humanos (Bevilacqua et al., 2001; Luz et al., 2001).

A grande capacidade de adaptação do vetor Lutzomyia longipalpis a ambientes urbanos, tanto no intra como no peridomicílio, e a diferentes temperaturas tem influenciado a dinâmica de transmissão da LV, caracterizando áreas endêmicas pela presença elevada do vetor e pelo grande número de casos caninos da doença (França-Silva et al., 2005; Margonari et al., 2006). A presença de outros animais no imóvel pode representar risco diferenciado para o homem (Borges et al., 2009), e estudos vêm sendo feitos com outros possíveis reservatórios e vetores incriminados na transmissão da doença (Silva et al., 2008; Paz et al., 2010).

Em Belo Horizonte, foi verificado que a infecção em cães precede a doença em humanos. Em 1992, foram diagnosticados cães positivos no município, e, em 1994, os primeiros casos humanos em áreas limítrofes do município de Sabará (Oliveira et al., 2001), onde um caso havia sido registrado em 1989 (Genaro et al., 1990). Inicialmente com característica focal (Oliveira et al., 2001), a LV tornou-se amplamente distribuída em todas as regionais, acometendo pessoas de condições socioeconômicas mais favoráveis e com aumento da ocorrência no grupo de adultos jovens (Lopes, 2009). O serviço público, apesar da intensificação das ações de controle, não conseguiu interromper a rápida expansão geográfica da doença e reduzir a incidência da $\mathrm{LV}$, que conta com mais de cem casos anuais (Leishmaniose..., 2008).

O objetivo desta pesquisa foi descrever as análises da série cronológica e determinar a tendência da leishmaniose visceral em humanos (LVH) e cães (LVC) para o município de Belo Horizonte, de 1993 a 2007.

\section{MATERIAL E MÉTODOS}

O município de estudo foi Belo Horizonte, localizado na Região Metalúrgica em Minas
Gerais. Situado entre os meridianos $43^{\circ}$ e $45^{\circ}$, possui uma área de $331 \mathrm{~km}^{2}$ e altitude de $852 \mathrm{~m}$. Predomina basicamente o clima tropical pelo regime sazonal de chuvas: estação úmida, chuvosa e seca. A temperatura média anual fica em torno de $21,1^{\circ} \mathrm{C}$ e há pequena variação de estações (Estatística..., 2008). Belo Horizonte conta com uma população de 2.412.937 habitantes (IBGE..., 2007), distribuída em nove regionais administrativas, distintas quanto às estatísticas de demografia, habitação, educação e saúde.

Como fonte de dados para análise da LVH e LVC, foram utilizados o quantitativo de casos notificados e registrados à Secretaria Municipal de Saúde de Belo Horizonte (SMSA-BH) e o total anual de amostras caninas examinadas e positivas, os quais estão disponibilizados no endereço eletrônico da Prefeitura de Belo Horizonte (Leishmaniose..., 2008). A gerência do Laboratório de Zoonoses da SMSA-BH repassou todos os resultados obtidos do diagnóstico da LVC, de 1998 a 2007, mensalmente. O total de óbitos de LVH e o censo canino de 2007 foram informados pela referência técnica da Gerência de Controle de Zoonoses da SMSA-BH.

Para o diagnóstico sorológico em cães, foram utilizados dois testes preconizados pelo Ministério da Saúde (MS): o enzyme-linked immunonosorbent assay (ELISA) como triagem e a imunofluorescência indireta (IFI) como confirmatório (Manual ..., 2006). Foi usado o seguinte critério de interpretação: positivo (ELISA e IFI reagentes ou IFI reagente); negativo (ELISA ou IFI não reagente); indeterminado (IFI indeterminada, independentemente do ELISA); a monitorar (ELISA reagente e IFI não reagente).

Realizou-se um estudo epidemiológico observacional, ecológico descritivo, da série cronológica de 1993 a 2007 desta zoonose. Para estimar a população de Belo Horizonte, foram utilizados os métodos aritmético e geométrico, para períodos inter e pós- censitário, respectivamente (Camel V, 1974). A análise da tendência dos coeficientes de incidência, de mortalidade e letalidade da LVH foi feita por regressão linear (Gujarati, 2000), com o uso do programa Stata 10.0. Para verificação da tendência e ciclicidade da LVC, analisou-se a função de autocorrelação total e parcial (Morettin 
e Toloi, 2006). As estimativas de modelagem dos dados foram feitas pelo pacote estatístico MINITAB. As análises de sazonalidade foram feitas com base no Box-plot e, também, pelo modelo de dessazonalização de séries temporais (Lapin e Whisler, 1976). O índice endêmico foi calculado para elaborar a curva endêmica, conforme preconiza Camel V (1974) para verificar se a ocorrência mensal da LVC apresentava valores de casos dentro ou fora da normalidade.

\section{RESULTADOS E DISCUSSÃO}

As estimativas da população humana para Belo Horizonte constam na Tab.1, juntamente com os coeficientes de incidência, mortalidade e letalidade para LVH, de 1994 a 2007. Belo Horizonte apresentou taxa de $1,35 \%$ de crescimento médio anual da população humana.

As análises apresentaram maior expressividade quando se observam dois períodos distintos na série cronológica da LV no município, tanto para humanos quanto para caninos: do início de casos a 2000 e de 2001 a 2007. Identificou-se aumento de 2,6 vezes entre as médias dos casos humanos dos dois períodos. Paralelamente, os coeficientes de incidência apresentaram média de 1,78 por 100.000 habitantes no período de 1994 a 2000 e de 4,32 no período de 2001 a 2007.

Tabela 1. Coeficientes de incidência, mortalidade e letalidade de leishmaniose visceral em humanos, Belo Horizonte, 1994 a 2007

\begin{tabular}{|c|c|c|c|c|c|c|}
\hline \multirow[b]{2}{*}{ Ano } & \multirow{2}{*}{$\begin{array}{l}\text { População } \\
\text { estimada }\end{array}$} & \multirow{2}{*}{$\begin{array}{l}\text { Número de } \\
\text { casos }\end{array}$} & \multirow{2}{*}{$\begin{array}{l}\text { Número de } \\
\text { óbitos }\end{array}$} & \multicolumn{3}{|c|}{ Coeficiente } \\
\hline & & & & $\begin{array}{l}\text { Incidência } \\
0 / 0000 \text { hab. }\end{array}$ & $\begin{array}{l}\text { Mortalidade } \\
0 / 0000 \text { hab. }\end{array}$ & $\begin{array}{c}\text { Letalidade } \\
\%\end{array}$ \\
\hline 1994 & 2100499 & 29 & 6 & 1,38 & 0,29 & 20,69 \\
\hline 1995 & 2127278 & 46 & 4 & 2,16 & 0,19 & 8,70 \\
\hline 1996 & 2154058 & 48 & 3 & 2,23 & 0,14 & 6,25 \\
\hline 1997 & 2180837 & 47 & 4 & 2,16 & 0,18 & 8,51 \\
\hline 1998 & 2207616 & 25 & 4 & 1,13 & 0,18 & 16,00 \\
\hline 1999 & 2234396 & 33 & 3 & 1,48 & 0,13 & 9,09 \\
\hline 2000 & 2261175 & 44 & 8 & 1,95 & 0,35 & 18,18 \\
\hline 2001 & 2289670 & 57 & 9 & 2,49 & 0,39 & 15,79 \\
\hline 2002 & 2318524 & 77 & 9 & 3,32 & 0,39 & 11,69 \\
\hline 2003 & 2347741 & 103 & 10 & 4,39 & 0,43 & 9,71 \\
\hline 2004 & 2377327 & 134 & 25 & 5,64 & 1,05 & 18,66 \\
\hline 2005 & 2407286 & 111 & 10 & 4,61 & 0,42 & 9,01 \\
\hline 2006 & 2437622 & 130 & 12 & 5,33 & 0,49 & 9,23 \\
\hline 2007 & 2468340 & 110 & 9 & 4,46 & 0,36 & 8,18 \\
\hline Total & & 994 & 116 & & & 11,67 \\
\hline
\end{tabular}

O ano de 1998 foi marcado pelo menor coeficiente de incidência, provavelmente devido à epidemia de dengue e ao uso de aspersão espacial de inseticidas, pela técnica de Ultra Baixo Volume (UBV), para o controle do vetor (Avaliação..., 2005). Este evento pode ter contribuído para diminuir a densidade de flebotomíneos e, consequentemente, a transmissão da LV neste ano. Porém, é fato que, em Belo Horizonte, a dengue torna-se prioridade sempre que ultrapassa o número de casos esperados, influenciando na diminuição das ações de controle da LVC.
Os coeficientes de incidência de 3,3 e 2,0 por 100.000 habitantes de Minas Gerais e Brasil (Casos..., 2007), respectivamente, em 2004, contrastam com o valor de 5,64 por 100.000 habitantes de Belo Horizonte, no mesmo ano. O município teve os maiores coeficientes de incidência em 2004 e 2006; este último de 5,33 por 100.000 habitantes. A rápida expansão da doença na Região Metropolitana de Belo Horizonte foi constatada pela elevação da proporção de municípios com notificações da doença desde a década de 1990 (Luz et al., 2001). Esta possibilidade de expansão da LV para centros urbanos já havia sido alertada por Deane e Deane (1962). 
A série de registros de $\mathrm{LVH}$ apresentou tendência crescente $(\mathrm{P}<0,05)$ do coeficiente de incidência de 1994 a 2007 (Fig. 1). Verificou-se tendência estacionária de 1994 a 2000 ( $\mathrm{y}=-$ $\left.0,0275 \mathrm{x}+1,8933 ; \mathrm{R}^{2}=0,0179 ; \mathrm{P}>0,05\right)$ e de 2001 a 2007 foi marginalmente significativa, $\mathrm{P}=0,07$ $\left(\mathrm{y}=0,3625 \mathrm{x}+2,8694 ; \mathrm{R}^{2}=0,5097\right)$, o que se explica pelo número estatisticamente reduzido de observações ao se analisar os dois períodos da série separadamente.

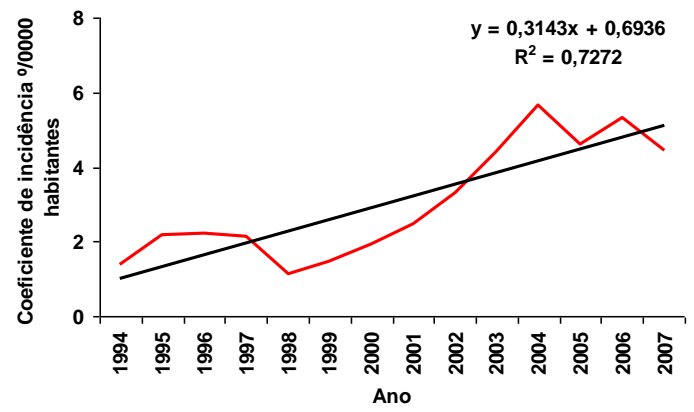

Figura 1. Tendência do coeficiente de incidência da leishmaniose visceral em humanos, em Belo Horizonte, 1994 a 2007.

O coeficiente de mortalidade apresentou tendência anual crescente $(\mathrm{y}=0,0329 \mathrm{x}+0,1103$; $\left.\mathrm{R}^{2}=0,3499 ; \quad \mathrm{P}<0,05\right), \quad \mathrm{e} \quad \mathrm{o} \quad$ de letalidade estacionária $\left(\mathrm{y}=-0,191 \mathrm{x}+13,553 ; \mathrm{R}^{2}=0,0287\right.$; $\mathrm{P}>0,05)$; este último com intensa irregularidade na série. Tais resultados tornam iminente a necessidade de o município reduzir o número de óbitos, considerando que o Brasil contou com um incremento de $86 \%$ no coeficiente de letalidade de 1994 a 2003, quando aumentou de 3,6\% para 6,7\% (Leishmaniose..., 2006), valores estes aquém dos registrados no município, mas que apontam para a necessidade do diagnóstico e tratamento precoces (Oliveira et al., 2006).

De 1993 a 2007, foram analisadas 1.492 .401 amostras de sangue canino com percentual de positividade de 5,9\%. O total anual de amostras e a porcentagem de cães positivos de 1993 a 1997 foram: $2.415(5,5 \%), 13.869(4,0 \%), 122.291$ $(3,2 \%), 108.022(4,3 \%), 142.286(3,2 \%)$. Os anos seguintes constam na Tab. 2. A porcentagem de positividade canina também está moldada na divisão da série cronológica, apresentando média de 4,0\% no período de 1993 a 2000 e de $8,0 \%$ de 2001 a 2007.

A tendência anual do percentual de cães positivos para LV em Belo Horizonte de 1993 a 2007 foi crescente, com a função quadrática explicando melhor o modelo $(\mathrm{P}<0,05)$, conforme mostra a Fig. 2. Semelhante ao observado na série da LVH quando dividida em dois períodos, o primeiro, de 1993 a 2000, apresenta tendência estacionária $\left(\mathrm{y}=-0,1824 \mathrm{x}+4,7724 ; \mathrm{R}^{2}=0,3028\right.$; $\mathrm{P}>0,05)$. Porém, de 2001 a 2007, a tendência apresenta-se crescente ( $\mathrm{y}=0,7156 \mathrm{x}+4,8886$; $\left.\mathrm{R}^{2}=0,7198 ; \mathrm{P}<0,05\right)$. Ressalta-se que estes dois períodos representam um número estatisticamente reduzido de observações para análise.

Tabela 2. Frequência de cães com resultados positivos, indeterminados e a monitorar para leishmaniose visceral em Belo Horizonte, 1998 a 2007

\begin{tabular}{cccccccccc}
\hline Ano & $\begin{array}{c}\text { Total de } \\
\text { amostras }\end{array}$ & Positivo & $\%$ & Negativo & $\%$ & Indeterminado & $\%$ & A monitorar & $\%$ \\
\hline 1998 & 54980 & 2426 & 4,41 & 52097 & 94,76 & 457 & 0,83 & - & - \\
1999 & 105636 & 4042 & 3,83 & 100473 & 95,11 & 977 & 0,92 & 144 & 0,14 \\
2000 & 106894 & 3316 & 3,10 & 102639 & 96,02 & 818 & 0,77 & 121 & 0,11 \\
2001 & 84512 & 4325 & 5,12 & 78892 & 93,35 & 1134 & 1,34 & 161 & 0,19 \\
2002 & 161918 & 9094 & 5,62 & 150985 & 93,25 & 1540 & 0,95 & 299 & 0,18 \\
2003 & 118403 & 10605 & 8,96 & 104889 & 88,59 & 2379 & 2,01 & 530 & 0,45 \\
2004 & 82181 & 6119 & 7,45 & 73586 & 89,54 & 2172 & 2,64 & 304 & 0,37 \\
2005 & 149470 & 11901 & 7,96 & 133921 & 89,60 & 3377 & 2,26 & 271 & 0,18 \\
2006 & 83881 & 8268 & 9,86 & 72217 & 86,09 & 3010 & 3,59 & 386 & 0,46 \\
2007 & 155643 & 14476 & 9,30 & 136361 & 87,61 & 3703 & 2,38 & 1103 & 0,71 \\
& & & & & & & & & \\
Total & 1.103 .518 & 74.572 & 6,76 & 1.006 .060 & 91,17 & 19.567 & 1,77 & 3.319 & 0,30 \\
\hline
\end{tabular}




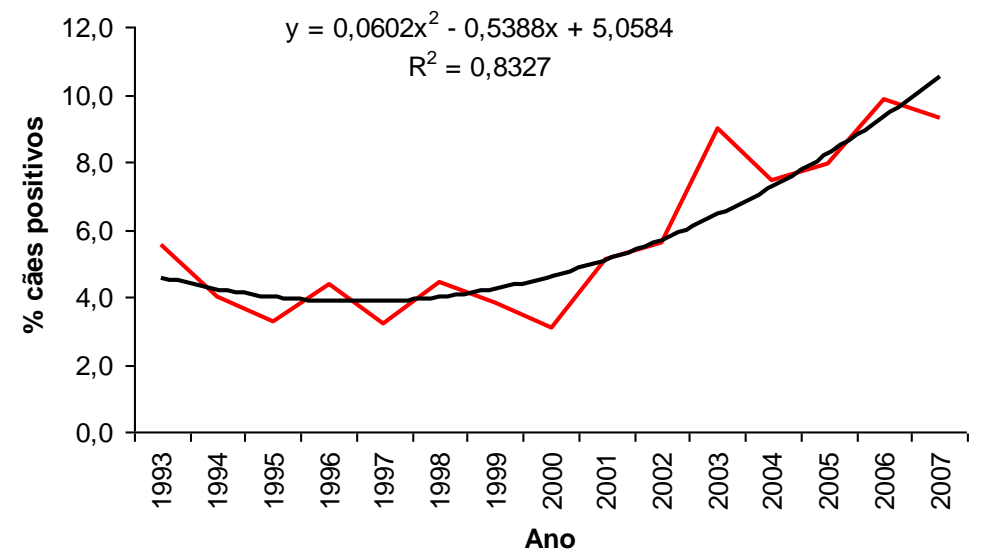

Figura 2. Tendência anual do percentual de cães positivos para leishmaniose visceral em Belo Horizonte, 1993 a 2007.

Para verificar a tendência das séries mensais, foram feitas as modelagens de proporções de positividade para LVC, de 1998 a 2007, via regressão linear, identificando-se as defasagens de autocorrelações e ajustando-se o modelo. Para os meses sem diagnóstico, devido à interrupção no repasse de kits pelo MS, utilizou-se interpolação das médias dos seis meses adjacentes (Fig. 3).

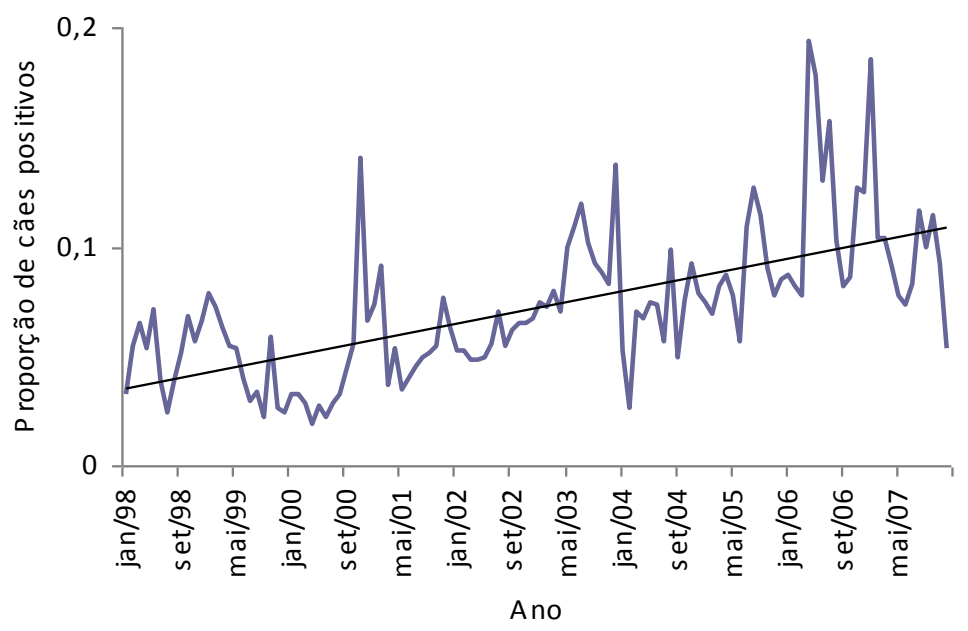

Figura 3. Tendência mensal da leishmaniose visceral em cães, com série de 1 a 120 observações, Belo Horizonte, 1998 a 2007.

O achado da tendência crescente foi confirmado pela função de autocorrelação total da série de Belo Horizonte, que apresentou queda lenta com o aumento das defasagens e, também, pela queda brusca da autocorrelação parcial, com um forte pico na defasagem de ordem 1 , o que é típico de modelos com tendência crescente. A análise de resíduos mostrou que o modelo ficou relativamente bem ajustado com resíduos independentes e homocedásticos. A análise de variância apresentou valor $\mathrm{P}<0,05$ e $\mathrm{R}^{2}$ ajustado de $53,0 \%$. Os parâmetros ajustados para as proporções de positividade de LVC resultaram na equação: Proporção $=0,0177+0,000312$ Tempo + 0,492 Proporção_1, em que: Tempo= termo de tendência e Proporção_1= valor da proporção do mês imediatamente anterior.

A análise dos coeficientes de incidência da série de LVH por regional, calculados por meio dos 
dados da Tab. 3, demonstrou aumento acentuado da média deste coeficiente do primeiro para o segundo período de 10,3 (Venda Nova), 8,2 (Pampulha), 5,7 (Noroeste), 5,0 (Oeste), 4,1
(Barreiro) e 3,0 (Norte). As regionais Centro-Sul, Leste e Nordeste mantiveram incidências semelhantes para os dois períodos, sendo baixa para a primeira e alta para as duas últimas.

Tabela 3. Distribuição dos casos humanos de leishmaniose visceral, de acordo com as regionais, Belo Horizonte, 1994 a 2007

\begin{tabular}{lccccccccccccccc}
\hline \multirow{2}{*}{ Regional } & \multicolumn{10}{c}{ Ano } & \multicolumn{10}{c}{ Total } \\
\cline { 2 - 12 } & 1994 & 1995 & 1996 & 1997 & 1998 & 1999 & 2000 & 2001 & 2002 & 2003 & 2004 & 2005 & 2006 & 2007 & \\
\hline Barreiro & 0 & 0 & 1 & 1 & 1 & 1 & 3 & 1 & 3 & 2 & 6 & 6 & 9 & 5 & 39 \\
Centro-Sul & 0 & 3 & 4 & 1 & 3 & 5 & 3 & 1 & 3 & 6 & 5 & 6 & 3 & 5 & 48 \\
Leste & 17 & 15 & 18 & 17 & 7 & 3 & 1 & 3 & 8 & 10 & 16 & 12 & 9 & 13 & 149 \\
Nordeste & 12 & 24 & 12 & 11 & 4 & 7 & 16 & 15 & 17 & 12 & 24 & 14 & 25 & 21 & 214 \\
Noroeste & 0 & 0 & 5 & 6 & 4 & 2 & 4 & 6 & 9 & 17 & 24 & 17 & 30 & 22 & 146 \\
Norte & 0 & 2 & 3 & 7 & 1 & 11 & 9 & 11 & 12 & 25 & 22 & 20 & 14 & 12 & 149 \\
Oeste & 0 & 1 & 1 & 1 & 2 & 0 & 4 & 3 & 3 & 3 & 10 & 11 & 10 & 7 & 56 \\
Pampulha & 0 & 0 & 1 & 1 & 0 & 0 & 3 & 8 & 5 & 11 & 6 & 10 & 3 & 6 & 54 \\
Venda & 0 & 0 & 2 & 0 & 3 & 4 & 1 & 9 & 17 & 16 & 21 & 14 & 24 & 17 & 128 \\
Nova & & & & & & & & & & & & & & & \\
Total & 29 & 45 & 47 & 45 & 25 & 33 & 44 & 57 & 77 & 102 & 134 & 110 & 127 & 108 & 983 \\
\hline
\end{tabular}

De modo geral, os primeiros anos da LVH e LVC, em Belo Horizonte, foram marcados por grandes dificuldades do município em operacionalizar as ações de controle da doença devido à inexperiência com esta zoonose, insuficiência de infraestrutura técnicooperacional e mesmo pela grande extensão e complexidade do município, o que favoreceu a instalação da epidemia (Avaliação..., 2005). Mesmo intensificando as ações de controle decorrentes de melhorias quantitativas e qualitativas na estruturação dos serviços, a doença alcançou coeficientes maiores e mudou o comportamento da tendência na série estudada. Uma possível explicação para o fato é a priorização de áreas de maior risco em detrimento daquelas de menor risco para LV (Morais et al., 2008). O MS reconhece a importância de se trabalhar estas áreas, porém com enfoque, também, nas áreas silenciosas (Manual ..., 2006).

Em relação ao diagnóstico laboratorial (Tab. 2), conforme registros, $1,8 \%$ das amostras apresentou resultado indeterminado e $0,3 \%$, resultado a monitorar, cuja soma representa 22.886 cães que necessitaram de uma segunda coleta de sangue para definição do resultado. Verificou-se, em outro estudo no município, que $38,4 \%$ dos cães inicialmente com resultado indeterminado positivaram, assim como $22,0 \%$ dos que apresentaram resultado a monitorar (Lopes et al., 2005). Esta situação implica a permanência de um quantitativo expressivo de cães no campo como reservatório da doença. Este quadro se agrava com a descontinuidade no repasse de Kits pelo MS para diagnóstico laboratorial, culminando com a priorização de coletas em cães por solicitação dos proprietários, consequentemente dificultando a realização dos inquéritos amostrais e censitários (Lopes, 2009).

A análise da distribuição mensal da frequência de cães positivos para LV não revelou existência de sazonalidade da doença em Belo Horizonte. $\mathrm{O}$ Box-plot apresentou comportamento estável das medianas mensais, durante todo o ano (Fig. 4). Este achado foi confirmado pelo modelo de dessazonalização de séries temporais. Estudos demonstram que a maior densidade de flebotomíneos coincide com o período de chuvas, de outubro a março, mas o vetor da LV é encontrado durante todo o ano (Monteiro et al., 2005; Margonari et al., 2006), mantendo o ciclo de transmissão.

Os métodos usados para explorar ciclicidade foram um Box-plot por ano e análises da função de autocorrelação, ambos após a retirada dos dados da tendência, com estudos sobre os resíduos. Pelo Box-plot, observou-se que os anos diferem em patamar e não obedecem a um perfil 
de variação regular que sinalize comportamento cíclico. São necessários mais anos de observações para estudar este aspecto da série, incluindo os anos iniciais da doença no município. Os resultados das autocorrelações desta série histórica decrescem rapidamente e não deixam evidências de comportamento cíclico regular. Séries cíclicas tendem a apresentar função de autocorrelação com valores de correlação altos em lags distantes do tempo, o que não ocorreu. A sazonalidade e a ciclicidade da LVH teriam sido avaliadas estatisticamente se os dados disponíveis fossem mensais.

O cálculo do índice endêmico sinalizou valores de positividade canina entre $4,8 \%$ e $12,4 \%$, de acordo com todos os meses do ano, como limites endêmicos para o ano de 2008 (Fig. 5).
O trabalho intenso desenvolvido pelo município para eutanásia de cães positivos para LV e a borrifação em domicílios estão registrados na Tab.4. Observa-se uma porcentagem comprometedora de cães com LV não retirados de campo durante toda a série, em média $20 \%$ do total de animais sorologicamente positivos, consequentemente mantendo o ciclo de transmissão da doença. O número de domicílios borrifados anualmente seguia um planejamento realizado por cada regional, com base em critérios preconizados pelo serviço de saúde, porém esta ação esteve associada, também, ao quantitativo de inseticida repassado pelo MS e à capacidade operacional do município. As ações de controle alcançam êxito quando trabalhadas de forma integrada (Manual ..., 2006; Morais et al., 2008).

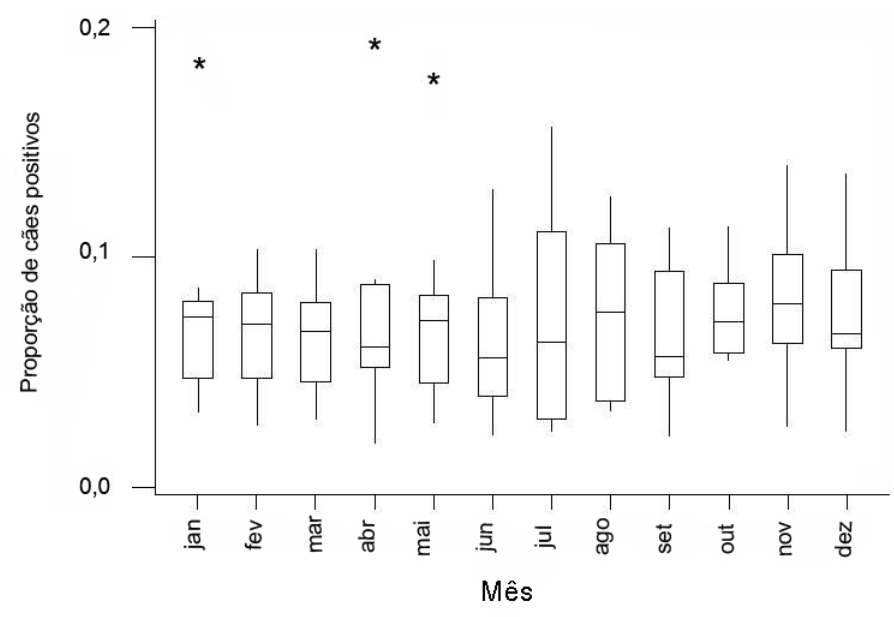

Figura 4. Box-plot das proporções mensais de positividade de leishmaniose visceral em cães, Belo Horizonte, 1998 a 2007.

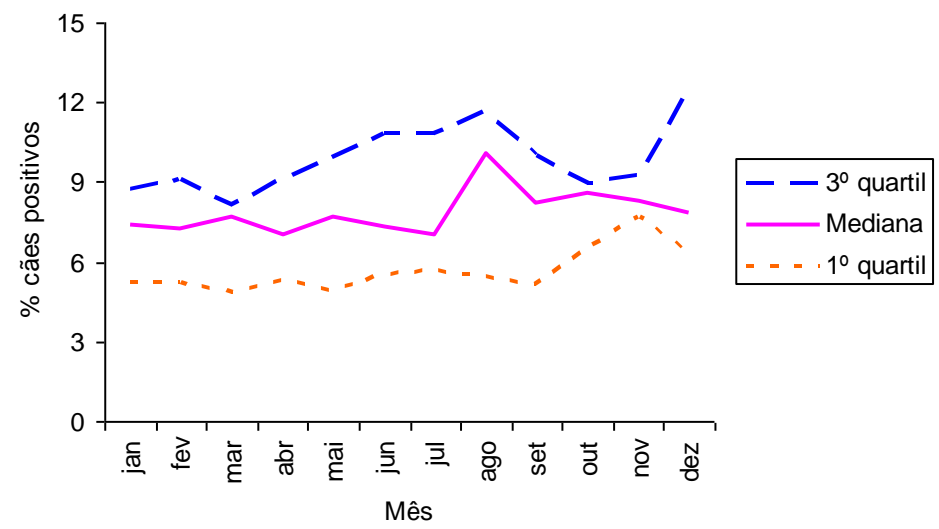

Figura 5. Curva endêmica da ocorrência de leishmaniose visceral em cães, Belo Horizonte, 2001 a 2007. 
Distribuição temporal e espacial...

Tabela 4. Porcentagem de cães eutanasiados com leishmaniose visceral e número de domicílios borrifados em Belo Horizonte, 1996 a 2007

\begin{tabular}{ccccccccc}
\multirow{2}{*}{ Ano } & $\mathrm{N}^{\circ}$ amostras & \multicolumn{2}{c}{ Cão positivo } & \multicolumn{2}{c}{ Cão eutanasiado } & \multicolumn{2}{c}{ Cão não retirado } & \multirow{2}{*}{ N $^{\circ}$ domicílios } \\
\cline { 3 - 7 } & analisadas & Total & $\%$ & Total & $\%$ & Total & $\%$ & borrifados \\
\hline 1996 & 108022 & 4691 & 4,34 & 3617 & 77,11 & 1074 & 22,89 & 46604 \\
1997 & 142286 & 4531 & 3,18 & 4332 & 95,61 & 199 & 4,39 & 22525 \\
1998 & 54980 & 2426 & 4,41 & 1419 & 58,49 & 1007 & 41,51 & 12443 \\
1999 & 105636 & 4042 & 3,83 & 2836 & 70,16 & 1206 & 29,84 & 46129 \\
2000 & 106894 & 3316 & 3,10 & 3150 & 94,99 & 166 & 5,01 & 61355 \\
2001 & 84512 & 4325 & 5,12 & 4096 & 94,71 & 229 & 5,29 & 53336 \\
2002 & 161918 & 9094 & 5,62 & 6414 & 70,53 & 2680 & 29,47 & 122824 \\
2003 & 118403 & 10605 & 8,96 & 7577 & 71,45 & 3028 & 28,55 & 125823 \\
2004 & 82181 & 6119 & 7,45 & 5652 & 92,37 & 467 & 7,63 & 151677 \\
2005 & 149470 & 11901 & 7,96 & 9197 & 77,28 & 2704 & 22,72 & 160671 \\
2006 & 83881 & 8268 & 9,86 & 8014 & 96,93 & 254 & 3,07 & 161258 \\
2007 & 155643 & 14476 & 9,30 & 10738 & 74,18 & 3738 & 25,82 & 113126 \\
& & & & & & & & \\
Total & 1353826 & 83794 & 6,19 & 67042 & 80,01 & 16752 & 19,99 & 1077771 \\
\hline
\end{tabular}

Os resultados deste trabalho ressaltam que as dificuldades de manter o diagnóstico associado à morosidade e o quantitativo parcial de cães destinados à eutanásia são, provavelmente, os elementos de maior peso que refletem na baixa resolutividade do programa em vigência.

Com base no censo canino de 2007 e na prevalência canina determinada a partir de amostral realizado neste mesmo ano, foi possível estimar o quantitativo de cães positivos por regional (Tab. 5). As avaliações dos coeficientes de incidência da LVH e prevalência da LVC, juntamente com dados de ocupação do espaço de cada regional, sugerem existir associação entre as densidades demográficas humana e canina e a frequência da ocorrência de LV. Este achado foi citado por Lopes (2009) como sendo uma provável condição favorável ao endemismo desta zoonose no município.

Tabela 5. Coeficientes de prevalência da leishmaniose visceral em cães distribuídos de acordo com as regionais de Belo Horizonte, 2007

\begin{tabular}{lccccc}
\multirow{2}{*}{ Regional } & \multirow{2}{*}{ Censo canino } & \multicolumn{2}{c}{ Amostras analisadas } & \multirow{2}{*}{$\begin{array}{c}\text { Coeficiente de } \\
\text { prevalência \% }\end{array}$} & $\begin{array}{c}\text { Estimativa de } \\
\text { cães positivos }\end{array}$ \\
\cline { 3 - 4 } Barreiro & 44673 & 13922 & 1019 & 7,3 & 3270 \\
Centro-Sul & 31828 & 10370 & 386 & 3,7 & 1185 \\
Leste & 37322 & 17420 & 1446 & 8,3 & 3098 \\
Nordeste & 37346 & 20859 & 2152 & 10,3 & 3853 \\
Noroeste & 40614 & 24686 & 2320 & 9,4 & 3817 \\
Norte & 29488 & 22949 & 2357 & 10,3 & 3029 \\
Oeste & 34586 & 9711 & 804 & 8,3 & 2863 \\
Pampulha & 24241 & 9976 & 946 & 9,5 & 2299 \\
Venda Nova & 41857 & 24388 & 2805 & 11,5 & 4814 \\
& & & & & \\
Total & 321955 & 154281 & 14235 & 9,2 & 29706 \\
\hline
\end{tabular}


O município enfrenta dificuldades no desenvolvimento das ações de controle, não só por problemas técnico-operacionais do próprio serviço, mas também pela crescente resistência dos proprietários em permitir o acesso dos agentes de saúde às suas residências para controle químico e coleta de sangue animal, pela recusa para entrega do cão positivo para eutanásia, e, ainda, pelo crescente número de cães sendo tratados por médicos veterinários, apesar da proibição pelo MS. A maioria dos cães não apresenta sinais clínicos da doença (Marzochi et al., 1985), mas pode participar como fonte de infecção em seu ciclo de transmissão. Ações educativas para melhorar a abordagem da população quanto ao conhecimento e às formas de prevenção da LV são de fundamental importância para o êxito do Programa de Controle da doença (Magalhães et al., 2009).

\section{CONCLUSÕES}

Em Belo Horizonte, a leishmaniose visceral apresenta tendência crescente dos coeficientes de incidência em humanos e de prevalência em cães, provavelmente devido à descontinuidade de execução das ações de controle normatizadas pelo Programa Nacional do Ministério da Saúde no Brasil. A manutenção e a expansão da doença poderiam, também, estar associadas à permanência prolongada de cães infectados não eliminados pelo serviço de saúde. As análises sobre a ocorrência da leishmaniose visceral em cães não apresentam características de distribuição sazonal, o que aponta para que ações de controle sejam permanentes em todos os meses do ano; não permitem, ainda, concluir pela existência ou não da ciclicidade. Os dados disponíveis sobre a ocorrência da leishmaniose visceral em humanos não permitem avaliar a existência de distribuição sazonal e cíclica da doença no município. A leishmaniose visceral em humanos e caninos tem ampla distribuição espacial, presente nas nove regionais administrativas de Belo Horizonte. A forma de ocupação do espaço urbano, provavelmente, influencia na diferenciação do risco de ocorrência da leishmaniose visceral em humanos e caninos.

\section{REFERÊNCIAS BIBLIOGRÁFICAS}

AVALIAÇÃO da ocorrência de leishmaniose visceral (LV) no município de Belo Horizonte, MG, 1993 a 2004. Belo Horizonte: Secretaria Municipal de Saúde, Gerência de Controle de Zoonoses, 2005. 13p. (Relatório técnico).

BEVILACQUA, P.D.; PAIXÃO, H.H.; MODENA, C.M. et al. Urbanização da leishmaniose visceral em Belo Horizonte, Arq. Bras. Med. Vet. Zootec., v.53, p.1-8, 2001.

BORGES, B.K.A.; SILVA, J.A.; HADDAD, J.P. et al. Presença de animais associada ao risco de transmissão da leishmaniose visceral em humanos em Belo Horizonte, Minas Gerais. Arq. Bras. Med. Vet. Zootec., v.61, p.1035-1043, 2009.

CAMEL, V.F. Estadística medica y de salud publica. Caracas: Venegrática, 1974. v.1, cap.32.10, p. 423-425.

CASOS confirmados de leishmaniose visceral, segundo UF de residência. Brasil, grandes regiões e unidades federadas, 1990 a 2006. 2007. Disponível em: <http://portal.saude.gov.br/portal/arquivos/pdf/ca sos_lv.pdf $>$ - atualizado em 18/09/07. Acessado em: 28 nov. 2008.

DEANE, L.M; DEANE, M.P. Visceral Leishmaniasis in Brazil: geographical distribution and transmission. Rev. Inst. Med. Trop. São Paulo, v.4, p.198-212, 1962.

ESTATÍ́STICA e mapas. Belo Horizonte: Prefeitura Municipal, 2008. Disponível em: <http://portalpbh.pbh.gov.br/pbh/ecp/comunidad e.do?app=estatisticas $>$. Acessado em: 29 jun. 2008.

FRANÇA-SILVA, J.C.; BARATA, R.A.; COSTA, R.T. et al. Importance of Lutzomyia longipalpis in the dynamics of transmission of canine visceral leishmaniasis in the endemic area of Porteirinha Municipality, Minas Gerais, Brazil. Vet. Parasitol., v.131, p.213-220, 2005.

GENARO, O.; COSTA, C.A.; WILLINS, P. et al. Ocorrência de calazar em área urbana da grande Belo Horizonte, MG. Rev. Soc. Bras. Med. Trop., v.23, p.121, 1990.

GUJARATI, D.N. Econometria básica. 3.ed. São Paulo: Makron Books, 2000. 846p. 
IBGE cidades @. Instituto Brasileiro de Geografia e Estatística, 2007. Disponível em: $<$ http://www.ibge.gov.br/cidadesat/topwindow.htm ?1>. Acessado em: 21 jun. 2008.

LAPIN, L.; WHISLER, W.D. Quantitative methods for business decisions. New York: Harcourt Brace Jovanovich, 1976. v.1.16, 770p.

LEISHMANIOSE visceral grave: normas e condutas. Brasília, DF: Ministério da Saúde, Secretaria de Vigilância em Saúde, 2006. 59p.

LEISHMANIOSE visceral. Belo Horizonte: Prefeitura Municipal, 2008. Disponível em: <http://portal1.pbh.gov.br/pbh/index.html?id_conte udo $=9479 \&$ id_nivel $1=-1 \&$ ver_servico $=\quad \mathrm{N}>$. Acessado em 17 out. 2008.

LEISHMANIOSE visceral no estado do RS [Porto Alegre]: Centro Estadual de Vigilância em Saúde, $2009 . \quad$ Disponível em: <http://www.saude.rs.gov.br/wsa/ portal/index.jsp?menu=noticias\&cod=36334>. Acessado em: 08 fev. 2010.

LOPES, E.G.P.; FONSECA, J.G.; PAGLIONI, D.N. et al. Histórico das amostras de sangue canino com resultado inconclusivo para leishmaniose visceral em Belo Horizonte, Minas Gerais, Brasil, 1999/2003. In: CONGRESSO MINEIRO DE EPIDEMIOLOGIA E SAÚDE PÚBLICA, 3., 2005, Belo Horizonte, MG. Anais... Belo Horizonte: Associação Mineira de Epidemiologia, 2005. CDROM

LOPES, E.G.P. Distribuição temporal e espacial da leishmaniose visceral em humanos e cães em Belo Horizonte-MG, 1993 a 2007. 2009. 95f. Dissertação (Mestrado) - Escola de Veterinária, Universidade Federal de Minas Gerais, Belo Horizonte, MG.

LUZ, Z.M.P.; PIMENTA, D.N.; CABRAL, A.L.V. et al. A urbanização das leishmanioses e a baixa resolutividade diagnóstica em municípios da Região Metropolitana de Belo Horizonte. Rev. Soc. Bras. Med. Trop., v.34, p.249-254, 2001.

MAGALHÃES, D.F.; SILVA, J.A.; HADDAD, J.P.A. et al. Dissemination of information on visceral leishmaniasis from schoolchildren to their families: a sustainable model for controlling the disease. Cad. Saúde Pública, v.25, p.1642-1646, 2009.

MANUAL de vigilância e controle da leishmaniose visceral. Brasília, DF: Ministério da Saúde, 2006. $120 \mathrm{p}$.
MARGONARI, C.; FREITAS, C.R.; RIBEIRO, R.C. et al. Epidemiology of visceral leishmaniasis through spatial analysis, in Belo Horizonte municipality, state of Minas Gerais, Brazil. Mem. Inst. Oswaldo Cruz, v.101, p.31-38, 2006.

MARZOCHI, M.C.A.; COUTINHO, S.G.; SABROZA, P.C. et al. Leishmaniose visceral canina no Rio de Janeiro - Brasil. Cad. Saúde Pública, v.1, p. 432-446, 1985.

MONTEIRO, E.M.; SILVA, J.C., COSTA, R.T. et al. Visceral leishmaniasis: a study on phlebotomine sand flies and canine infection in Montes Claros, State of Minas Gerais. Rev. Soc. Bras. Med. Trop., v.38, p.147-52, 2005.

MORAIS, M.H.F.; MAGALHÃES, D.F.; ARAÚJO, V.E.M. et al. Sustentabilidade das ações de controle da leishmaniose visceral e as implicações da priorização de áreas de risco na expansão da doença no distrito sanitário noroeste de Belo Horizonte, Minas Gerais, 2006 a 2008. Rev. Soc. Bras. Med. Trop., v.41, Supl.III, p.77-81, 2008.

MORETTIN, P.A.; TOLOI, C.M.C. Análise de séries temporais. 2.ed. São Paulo: Edgard Blucher, 2006. 538p.

OLIVEIRA, C.L.; ASSUNÇÃO, R.M.; REIS, I.A. et al. Spacial distribution of human and canine visceral leishmaniasis in Belo Horizonte, Minas Gerais State, Brazil, 1994-1997. Cad. Saúde Pública, v.7, p.1231-1239, 2001.

OLIVEIRA, A.L.L.; PANIAGO, A.M.M.; DORVAL, M.E.C. et al. Foco emergente de leishmaniose visceral em Mato Grosso do Sul. Rev. Soc. Bras. Med. Trop., v.39, p. 446-450, 2006.

PAZ, G.F.; RIBEIRO, M.F.B.; MAGALHÃES, D.F. et al. Association between the prevalence of infestation by Rhipicephalus sanguineus and Ctenocephalides felis felis and the presence of antiLeishmania antibodies: a case-control study in dogs from a Brazilian endemic area. Prev. Vet. Med., v.97, p.131-133, 2010.

SILVA, A.V.M.; CÂNDIDO, C.D.S.; PEREIRA, D.P. et al. The first record of American visceral leishmaniasis in domestic cats from Rio de Janeiro, Brazil. Acta Trop., v.105, p.92-94, 2008. 